\title{
Universal fixture for Friction Stir Welding for Conventional Milling Machine: A Review
}

\author{
Mr. Sudeep S Zirmire ${ }^{1}$; Dr. Arvind L. Chel $^{2}$ \\ Student, Mechanical engineering, JNEC - College of Engineering ${ }^{1}$; \\ Assot. Professor, Mechanical engineering, JNEC - College of Engineering ${ }^{2}$ \\ sudeep.zirmire@gmail.com ${ }^{1}$; dr.arvindchel@gmail.com ${ }^{2}$
}

DOI $<$ 10.26821/IJSHRE.8.10.2020.8102>

\begin{abstract}
This review article focuses on the different clamping technique used in Friction Stir Welding process. Variable thickness and different width of plates can be machined with modifying fixture. Fixtures also help to simplify metalworking operations performed on special equipment. Economically, speaking the most valuable function of a fixture is to reduce operation costs. Friction stir welding (FSW) is an innovative welding method commonly known as a solid-state welding process. This opens up whole new areas in welding technology for research scholar and engineers. The modified conventional milling machine can be used for friction stir welding process with less cost. It also saves machine arrangements time. This work presented
\end{abstract}

a simplified design of fixtures can be used for friction stir welding.

Keywords: Friction stir welding, tool geometry, clamp design.

\section{INTRODUCTION}

Friction stir welding (FSW) is a solid-state joining process developed at TWI Ltd in 1991. FSW works by using a non-consumable tool, which is rotated and plunged into the interface of two workpieces. The tool is then moved through the interface and the frictional heat causes the material to heat and soften. The rotating tool then mechanically mixes the softened material to produce a solid-state bond. The FSW process is illustrated in Figure 1.

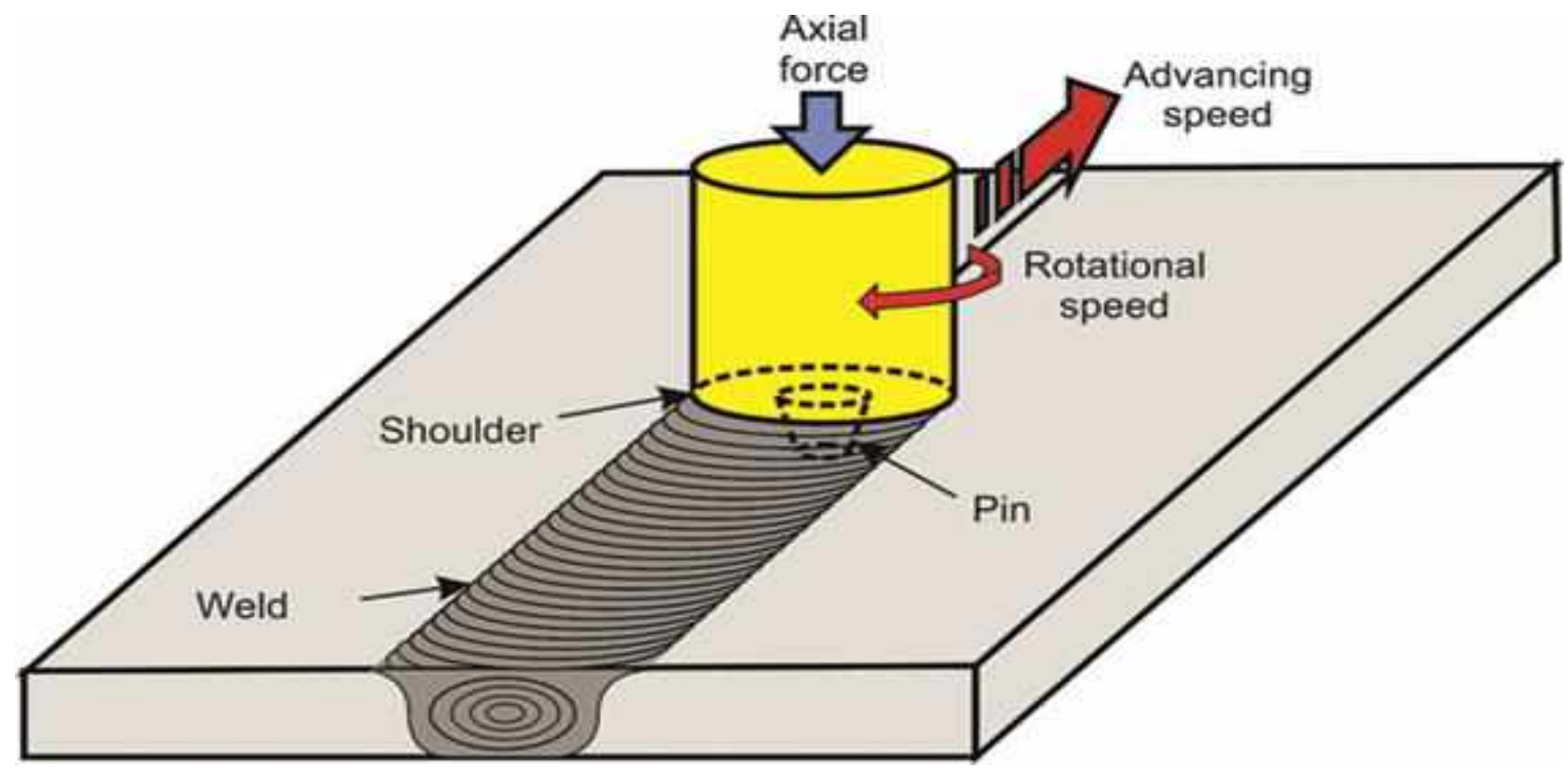

Fig 1: FSW Process 
Volume 8 Issue 10 October 2020

\section{FUNCTION OF FIXTURE}

Fixtures are rigid and sturdy mechanical devices which allow fast and precision machining with reliable quality, interchangeability, and lead time reduction. As a work-holding device, fixtures do not position, guide, and locate the cutting tool, as it is achieved by making necessary adjustments on the machine. FSW is performed on a retrofitted vertical milling machine. To support the metal plates to be joined, the fixture is designed and fabricated using different machining processes. The main purpose of a fixture for friction stir welding is to hold the workpieces in position during welding.

\section{MATERIAL OF FIXTURE}

Mild steel is the material used for manufacturing the fixture base plate, clamps and stopper. Since mild steel has high strength and toughness which is re-quired to withstand unbalanced force and pressure during FSW operation. The selection of tool rotational speed and traverse speed are crucial for heat generation and the forces applied on the tool should be minimum in order to create good flow of material around the tool pin so chosen material is good for fixture development for sound friction stir welding. After the fabrication, it is often heat-treated for stress reduction as its main objective is to accommodate and support the job.

\section{DESIGN OF FIXTURE}

To ensure that the jigs and fixtures as production tools and work-holding devices are able to produce interchangeable and duplicate parts with high degree of precision, efforts are made at the design stage to incorporate important features that will ensure that quality components are assembled and machined properly [1].

\subsection{Clamping Devices}

Without sacrificing efficiency and effectiveness, the clamping devices must be very simple and easy to operate. Apart from holding the work-piece securely in place, the strong point of clamping devices is its ability to withhold the strain of the cutting tool during operations. The bench vice is a popular example of a clamping device. The need for clamping the workpiece on the jig or fixture is to apply pressure and press it against the locating components, thereby fastening it in the right position for the machining tools [1].

\subsection{Locating Devices}

Made with hardened steel and with different designs, the pin is the most popular device applied for the location of work-piece in jigs and fixtures. The pin's shank is press-fitted or driven into a fixture. The locating width of the pin is made bigger than the shank to stop it from being pressed into fixture body because of the weight of the cutting tools or work-piece [1].

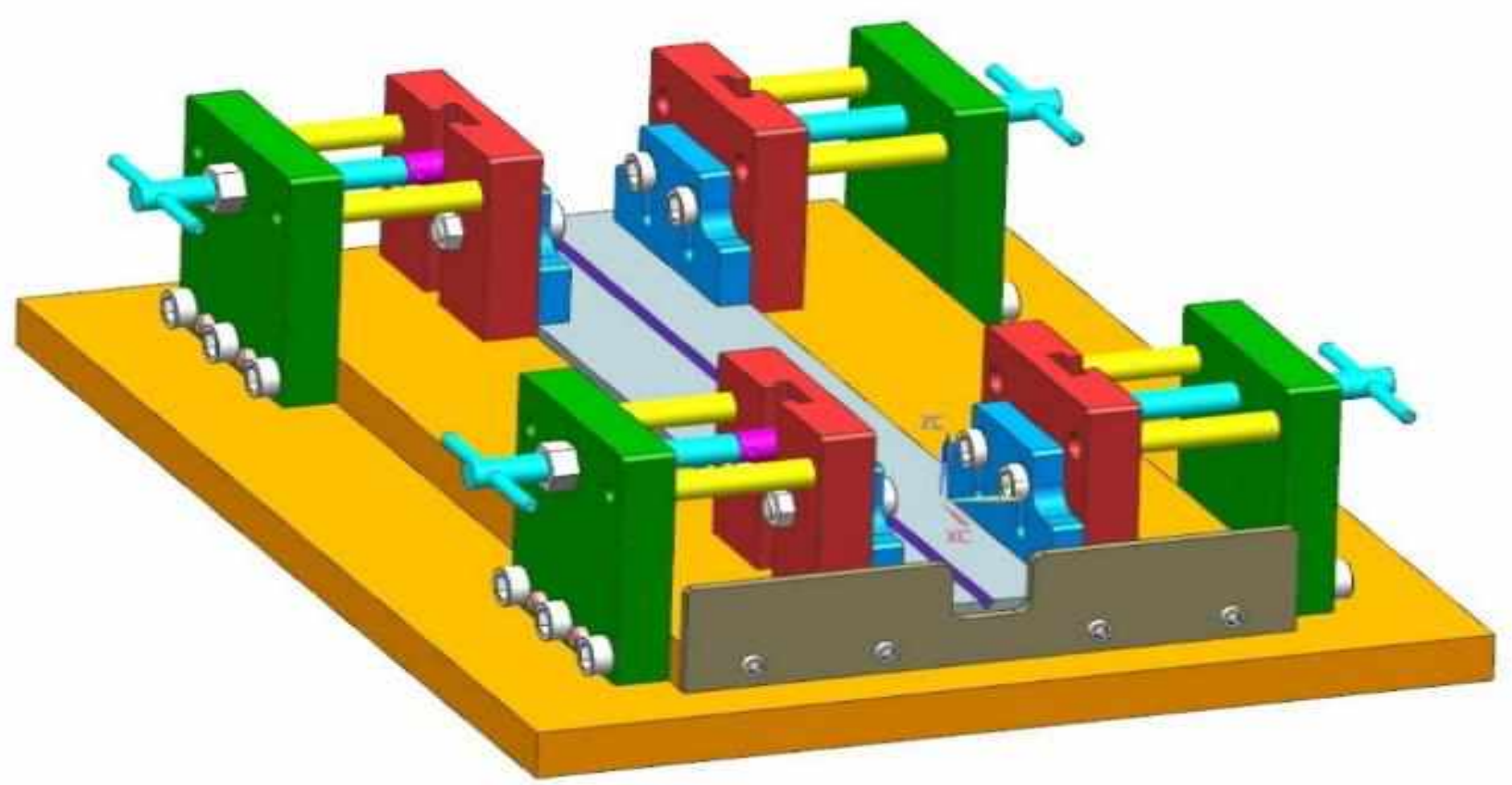

Fig 2: FSW Universal Fixture 
Volume 8 Issue 10 October 2020

\section{COMPONENTS OF FIXTURE}

Table 1. List of Parts

\begin{tabular}{|c|c|c|}
\hline Sr. No & Component Name & Quantity \\
\hline 01 & Base Plate & 01 Nos \\
\hline 02 & Side Plate & 04 Nos \\
\hline 03 & Support Plate & 04 Nos \\
\hline 04 & Pressure Plate & 04 Nos \\
\hline 05 & Lock Bars \& Nuts & 04 Nos \\
\hline 06 & Guide Bush & 08 Nos \\
\hline 07 & Stopper Plate & 01 Nos \\
\hline 08 & Allen Bolts & 12 Nos \\
\hline 09 & Allen Bolts \& Nuts & 08 Nos \\
\hline 10 & Allen Bolts & 04 Nos \\
\hline 11 & Dowel Pins & 04 Nos \\
\hline
\end{tabular}

\subsection{Base Plate}

It maintains the position of the welding work piece from going apart in plunging phase and in operation. It sustains at high temperature reaching during welding operation and in extreme condition, the welded work piece is likely to remain stuck to the fixture compromising both the fixture integrity and soundness of the joint [4].

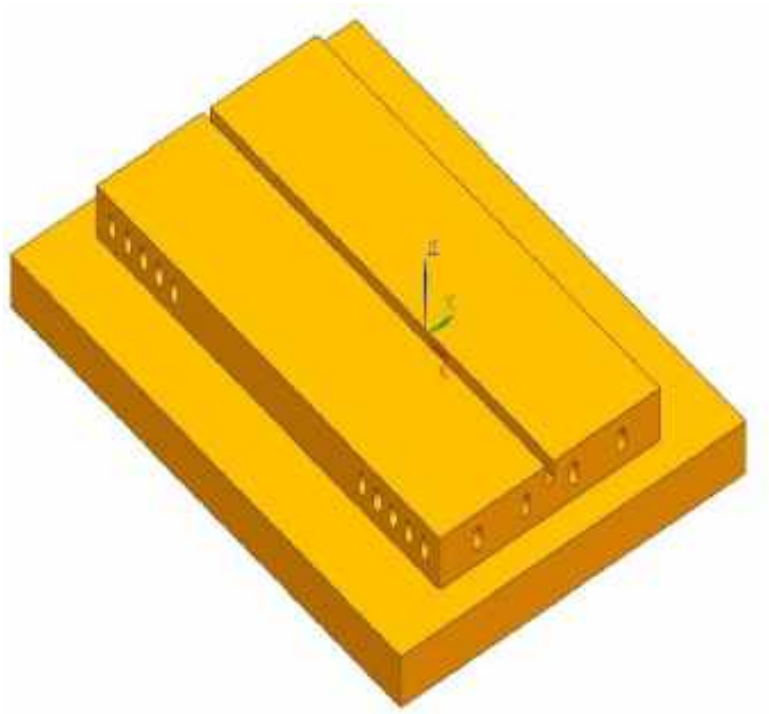

Fig 3: Base Plate

\subsection{Side Plate}

Side plate is bolted to base plate by three Allen bolts and located by two dowel pins. The function of side plate is to guide and hold the locking arrangement.

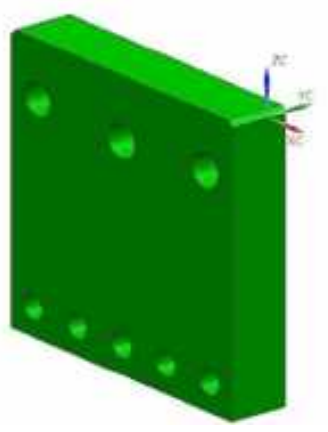

Fig 4: Side Plate

\subsection{Support Plate}

The main function of this plate is adjusting the different width of workpiece while clamping. It also helps in preventing the cross sliding of workpieces during welding. It is guided by guide bush and motion controlled by lock bar and nut.

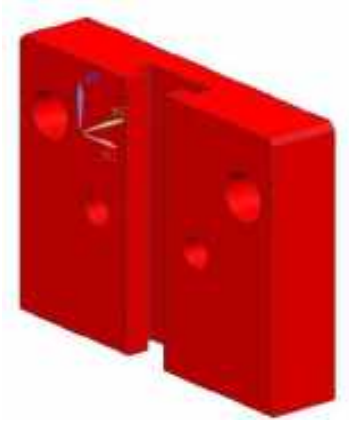

Fig 5: Support Plate

\subsection{Pressure Plate}

The pressure plate, which is bolted onto the support plate, presses the workpiece against the base plate. It also helps in preventing the vertical moment of workpieces during welding. The different thickness of welding plates can adjustable by vertical moment of plate. 


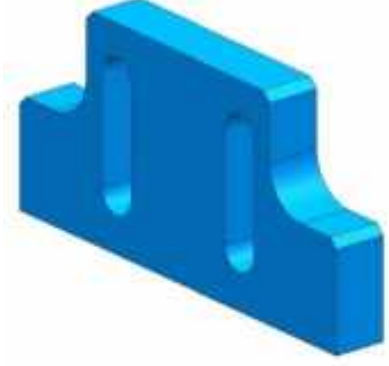

Fig 6: Pressure Plate

\subsection{Lock Bar \& Nuts}

Lock nuts protect against loosening, however, by featuring a design that increases the nut's resistance to vibrations. The head of lock bar rest inside the T-slot of support plate and other threaded end is in side plate adjusted by hexagonal nut.

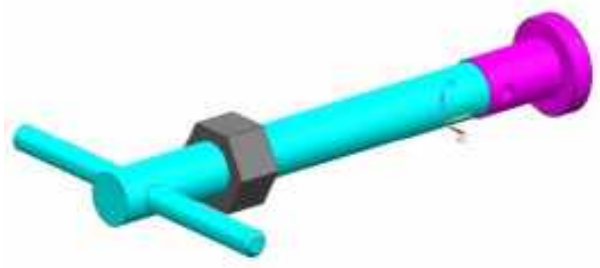

Fig 7: Lock Bar \& Nut

\subsection{Guide Bush}

A cylindrical part that function as a guide to position the lock bar and support plate. Two guide bushes are used to aligning a plate properly with the work.

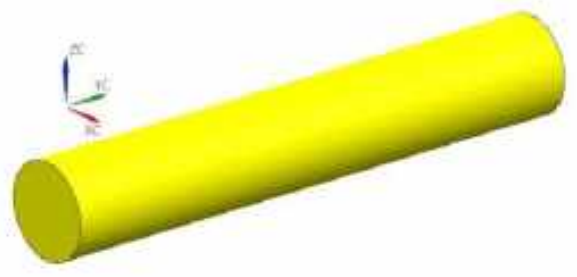

Fig 8: Guide Bush

\subsection{Stopper Plate}

Plate stoppers are used mainly for sliding prevention. Plate stoppers may also be used to arrest the movement of the workpiece when tool is fed.

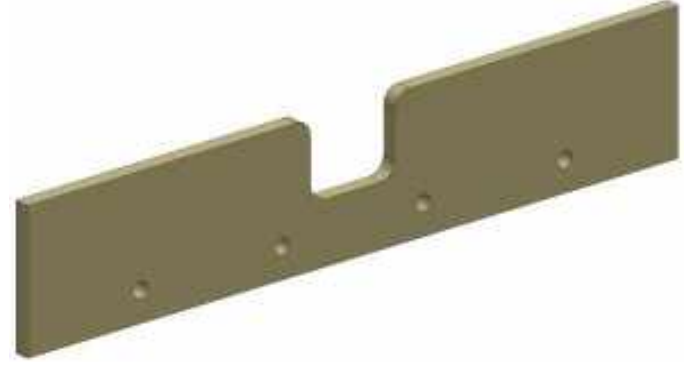

Fig 9: Stopper Plate

\subsection{Fasteners}

A bolt is a type of fastener which is used to join two parts together. The bolts join the part nonpermanently. Nuts are also used on the bolts to make the fastening process more effective.

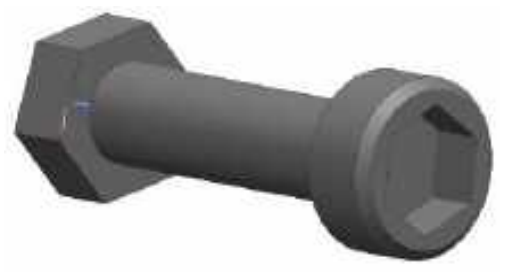

Fig 10: Allen Bolt \& Nut

Hardened and precisely shaped dowel pins are used to keep machine components in accurate alignment. They are also used as location guides for adjacent machine parts and to keep the two plates of meeting in alignment.

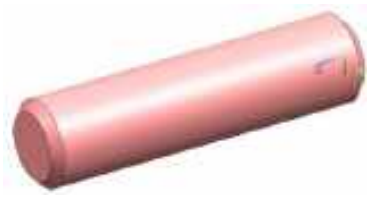

Fig 11: Dowel Pin

\section{REVIEW ON FSW FIXTURE FOR CONVENTIONAL VERTICAL MILLING MACHINE}

A number of research papers have been published on the clamping method of friction stir welding. A brief review of some selected references on this topic is presented.

T. Minton and D.J. Mynors. [3] described the procedures of using conventional manual milling machine whose operating ranges and speed values are 
Volume 8 Issue 10 October 2020

for Friction Stir Weld (FSW) butt joints. Parkson Vertical Mill Type A was employed for trials on $6.3 \mathrm{~mm}$ and $4.6 \mathrm{~mm}$ thick aluminium 6082-T6 sheet, At the initial level, it was unknown about the capability of milling machine for FSW, for this a single generic tool was designed for the $6.3 \mathrm{~mm}$ sheet and used for the $4.6 \mathrm{mmsheet}$. The tools were manufactured from $19 \mathrm{~mm}$ diameter silver steel. The pieces to be welded were placed in butt position, bolted to a steel backing plate which was bolted directly to the machine's feed table. They found that the quality of weld with lesser thickness is not as good as for thicker plate i.e. 6.3 $\mathrm{mm}$. They further suggested to access the effect of change of tool geometry for improving weld quality of $4.6 \mathrm{~mm}$ plates for future work. But through this work FSW was successfully achieved for aluminium plate with the help of milling machine [5].

Esther T. Akinlabi et.al. [6] designed and modified a clamping and support system in a reconfigured milling machine to produce friction stir welding joints. The redesigning of a milling was done to produce friction stir welds. The objective of this design was to develop a clamping and support system for a reconfigured milling machine to be utilized for producing friction stir welds with lesser vibration. They suggested that different thickness plates can be clamped and welded with proposed design. The performance analysis showed that the concept can be used for friction stir welding to be performed by using a typical milling machine. The inexpensive milling machine adaptations allow for the conversion of any milling machine into a specialized Friction Stir Welding machine which is suitable for research purposes [6].

Mohd. Anees Siddiqui, S. A. H. Jafri, P. K. Bharti, Pramod Kumar discussed as friction stir welding is used for joining of two plates which by applying compressive force that requires fixtures over the work table. Process parameter includes tool geometry, joint design and welding parameters which are to be kept in mind while performing FSW [7].

Abhishesh Mishra, Rajnish Singh, Saadat A. Rizvi They made fixture from base plate, clamp and stopper fitted on machine table and it is usable for friction stir welding on this retrofitted vertical milling machine. Fixture is adjustable and easy to operate which leads to no shifting of welding workpiece during FSW. They found good vibration absorbing capacity with good axial load carrying capacity which leads to significant defect free friction stir welding. On variable condition sound FSW found without any distortion of weld material due to no excess heat effect. They had mentioned scope for automation for clamping and welding [4].

\section{CONCLUSION}

For future research directions, it is recommended to improve the present fixture for further investigations. While it is specially designed to use on conventional milling machine for FSW research, it can be used for other machines by using different configuration methods. Fixture is adjustable and easy to operate which leads to no shifting of welding workpiece during FSW. This design leads to significant defect free friction stir welding. Lastly this review paper will open new doors of research for design of different clamping systems for different thicknesses so that conventional milling machines can be utilized in FSW for different materials with less investment.

\section{REFERENCES}

[1]. Charles Chikwendu Okpala, Ezeanyim Okechukwu C. 'The Design and Need for Jigs and Fixtures in Manufacturing' Science Research in Volume 3, Issue 4, August 2015, Pages: 213-219

[2]. L. Fratini (2)*, F. Micari (1), G. Buffa, V.F. Ruisi 'A new fixture for FSW processes of titanium alloys' CIRP Annals - Manufacturing Technology 59 (2010) 271-274

[3]. L.V. Kamblea*, S.N. Somanb, P.K. Brahmankarc 'Understanding the Fixture Design for friction stir welding research experiments' Materials Today: Proceedings 4 (2017) 1277-1284

[4]. Abhishesh Mishra, Rajnish Singh, Saadat A. Rizvi 'Fabrication and Vibration Analysis on Friction Stir Welding Fixture for Mass Production' Mechanics and Mechanical Engineering Vol. 21, No. 3 (2017) 531-540

[5]. T. Minton, D.J. Mynors, Utilisation of engineering workshop equipment for friction stir welding, Journal of Materials Processing Technology, Elseviers, 2006

[6]. Esther T. Akinlabi Adrian C. S. Levy, Stephen A. Akinlabi., Design of a Support System for a Reconfigured Milling Machine to Achieve Friction Stir Welds, Proceedings of the World Congress on Engineering 2013 Vol I, WCE 2013, July 3 - 5, 2013, London, U.K 5

[7]. Mohd. Anees Siddiqui, S. A. H. Jafri, P. K. Bharti, Pramod Kumar 'Friction Stir Welding as a Joining 
ijournals: International Journal of Software \& Hardware Research in Engineering (IJSHRE)

ISSN-2347-4890

Volume 8 Issue 10 October 2020

Process through Modified Conventional Milling Machine: A Review' international journal of innovative research \& development Vol 3 Issue 7 July,2014 